\title{
Magnesium Sheet; Challenges and Opportunities
}

\author{
Faramarz Zarandi and Stephen Yue \\ McGill University \\ Canada
}

\section{Introduction}

Where light-weight components are desired, e.g. in automotive and aerospace applications, magnesium can provide an important advantage over other structural materials such as aluminum and steel. The density of magnesium is two thirds that of aluminum and a quarter that of galvanized steel. The combination of low density and reasonable strength of magnesium leads to a specific strength, which is much higher than that of steel or aluminum. Stiffness is often as important as strength and, with respect to bending stiffness, magnesium offers major advantages over both steel and aluminum. Using more magnesium would significantly decrease the weight of automobiles, which is one of the important goals in automobile design. However, usage of magnesium lags far behind that of aluminum. To date, most magnesium applications in the automobile industry are in the form of die cast parts. Wrought magnesium, particularly in the form of sheet, represents a tremendous growth opportunity in the application of magnesium, e.g. inner door panel, engine bonnet, seat components, roof, and fenders. The use of magnesium sheet is, however, severely limited because of: (a) the high cost of magnesium sheet, (b) the poor room temperature ductility of magnesium, and (c) the relatively high propensity to corrosion.

Sheet materials are required to display sufficient formability when subjected to bending stresses during fabrication into parts. The poor plastic flow characteristics of magnesium at room temperature have considerably hampered its sheet applications. Essentially, because magnesium has a hexagonal close packed $(h c p)$ structure, active slip systems at low temperatures are mainly limited to those involving basal planes. This is because the critical resolved shear stress (CRSS) for basal plane slip in magnesium single crystal is 100 times lower than that for non-basal plane slip (prismatic or pyramidal planes) near room temperature. Thus, the distribution of basal planes (0001) in magnesium plays an important role in determining formability at low temperatures. As the temperature increases, the CRSS of the non-basal slip systems decreases and, therefore, there is a significant increase in formability. Consequently, sheet forming at elevated temperatures is one possibility that is being contemplated, and there is considerable ongoing research in this general area, including those concerned with the viability of superplastic forming. In this chapter, the challenges to the production of magnesium sheet and the route toward overcoming them are explained. Then, deformation characteristics of magnesium and associated mechanisms are discussed. 


\section{Magnesium sheet production}

Rolling is the usual process for sheet production. In early magnesium rolling practice, only extruded slabs were rolled. It was believed that an extruded slab had a more uniform microstructure and, hence, better rolling properties. The method of eliminating as-cast structure by press forging before rolling has also been extended to the production of sheet. This method offers no advantages over extrusion but is a useful alternative. Magnesium sheet can be also produced directly from cast slabs depending on the alloy, the degree of reduction, and final application of the sheet (Alico, 1945).

Magnesium sheets are conventionally made from magnesium shapes that are preconditioned cast slabs. In order to eliminate the as-cast structure, pre-conditioning is usually performed by heat treatment and hot deformation such as hot rolling. In laboratories, the ascast ingot is usually pre-conditioned by hot extrusion, where large amounts of compressive deformation can be applied. AZ31, which has a nominal chemistry of Mg-3wt $\% \mathrm{Al}-1 \mathrm{wt} \% \mathrm{Zn}$, is the magnesium alloy currently favored for sheet production. Normally, the alloy is cast into a slab form and pre-conditioned in a block slab cogging mill. One drawback is that the slab surface is oxidized at high temperature. During rolling, the oxide film can be rolled into the sheet metal and deteriorate the sheet quality. Even though the oxide layer can be removed by chemical or mechanical demolition, these processes cause recesses, i.e. rough uneven and contaminated surfaces through a thickness of 10 to $15 \mathrm{~mm}$ that must be eliminated. On the surface, enriched contamination, compact oxide and inclusions, particles of second phases as well as microscopic and macroscopic defects, e.g. pores, increase the sheet susceptibility to cracking upon further deformation (Poss, 2003).

In order to prevent macrosegregation of the alloying elements, wrought magnesium alloys are preferably cast by Direct Chill (DC) machines. Despite rapid solidification of the narrow melt bath, the average grain size of the cast billet is large, depending on the billet diameter and casting parameters. In some cases, the cast billet has to be initially hot worked in order to avoid the brittleness effect of large grains and improve hot workability. The DC magnesium slab is often $300 \mathrm{~mm}$ by $1 \mathrm{~m}$ in cross section and $2 \mathrm{~m}$ long. The slab is normally first homogenized, for AZ31 typically at $480^{\circ} \mathrm{C}$, for several hours and hot rolled on a reversing hot mill to 5-6 mm thick. The hot rolling is normally performed at about $60 \mathrm{mpm}$. In the first rolling passes, the allowable reduction per pass is limited to $5-10 \%$ by the coarse grain structure of the cast feedstock which causes cracking. It is only after recrystallization and grain refinement that the strain per pass can be increased to $30-60 \%$. The contact time between the slab and the rolls of the breakdown mill is quite short, and these rolls are seldom preheated. The rolls are often lubricated in the final passes. However, the best lubricant used today does not entirely solve one of the problems of magnesium hot rolling, namely, roll pickup in which magnesium oxide and metal cling to the rolls. As the rolling continues, this so-called roll pickup may be re-deposited upon the sheet, calling for careful cleaning at later stages. After breakdown, the slab is reheated to $315-370{ }^{\circ} \mathrm{C}$ and rolled in a flat or a coil finishing mill to final thickness. Prior to cold rolling, the hot rolled sheet is generally annealed at around $370^{\circ} \mathrm{C}$ to ensure complete softening. Cold rolling is then carried out at speeds of 30 to $120 \mathrm{mpm}$. For rolling from $2 \mathrm{~mm}$ or thereabouts to thinner gauges, the process consists of a series of cold rolling operations with intermediate annealing treatments. The amount of reduction per pass varies from 1 to $5 \%$ and is sometimes as high as $10 \%$ in thin gauges. This latter part of the rolling process is time consuming with high operating costs and progressively tends towards lower metal yields. 
Such a technology also requires expensive quality control procedures and substantial investment in equipment (Dow Chemical Company, 1943; Allen et al., 2001; Bach et al., 2006). This means that a standard magnesium sheet production consists of a complex DC casting, a homogenization treatment, and approximately 12-18 hot rolling passes in 2-3 heats. This is why magnesium sheet is expensive, even though the raw material costs can easily compete with aluminum.

Strip casting technology has been successfully used to produce aluminum sheet directly from the melt. This is also a potential process for production of magnesium sheet with considerably lower number of rolling passes. Therefore, the produced sheet would be much less expensive than the conventionally produced sheet. Single-belt and twin-belt strip casting technologies have been also studied. The principal advantages of these processes are that alloys with large solidification ranges can be produced easily and a high surface quality can be achieved owing to the 'moving die' principle. The twin-belt caster is more favored as less protective gases are required to protect the melt and the symmetrical cooling condition results in a homogeneous fine-grained microstructure. Nevertheless, the capability of twinroll casting process, among other strip casting processes, has been more eagerly examined for magnesium sheet. Magnesium alloy strip with thicknesses less than 5-6 $\mathrm{mm}$ can be produced directly from the melt by twin-roll casting, reducing capital investment and operational costs (CSIRO, 2003). Commercial quality sheet samples from 2.3 to $5 \mathrm{~mm}$ thick have been successfully cast in standard alloys (AZ31, AZ61, AM60 and AZ91), along with a number of new magnesium wrought alloys. These samples have been rolled down to 0.5-0.6 mm gauges, using a novel finish-rolling schedule developed specifically for cast magnesium alloy sheet (Liang \& Cowley, 2004). Near-rapid solidification achieved in twin-roll casting, through cooling rates ranging from 300 to several thousands of degrees per second, can potentially improve alloy properties by improving the homogeneity of microstructures (especially minimizing the size of manganese-rich particles), refining grain size, reducing segregation, increasing solid solubility, enhancing precipitate nucleation within the matrix, and generating a distribution of fine precipitates (CSIRO, 2003 \& Masoumi et al., 2010a). The microstructure of a twin-roll cast AZ31 alloy, with about $5 \mathrm{~mm}$ thickness, consists of a columnar-grain zone from the surface to the mid-thickness region and an equiaxed-grain zone in the mid-thickness region. The secondary-dendrite arm spacing is within 5-6.5 $\mu \mathrm{m}$ range through the thickness and the width of the strip, which is much smaller than $\sim 34 \mu \mathrm{m}$ of a DC ingot AZ31 alloy (Nakaura \& Ohori, 2005). The small dendrite arm spacing in a twin-roll cast AZ91 alloy improved the workability at elevated temperatures. The secondary-dendrite arm spacings can be transformed into recrystallized grains of 9-10 $\mu \mathrm{m}$ in diameter by hot rolling (Allen et al., 2001). Such a small grain size is expected to benefit superplasticity at elevated temperatures.

Hot-rolled twin-roll cast AZ91 sheet has exhibited an improvement of $60 \%$ in yield stress and $17-40 \%$ in UTS (Ultimate Tensile Strength) as compared to the sheets produced from the sand-cast (T6 temper) and die-cast (F temper) slabs (Allen et al., 2001). The fine precipitation within grains has definitely contributed to this improvement in mechanical properties. Moreover, it has been noted that casting AZ31 alloy close to the liquidus temperature promotes formation of spherical or nodular primary a-Mg, which is favorable for improved workability of AZ31 alloy (Yang et al., 2005). On the other hand, x-ray diffraction has shown that twin-roll casting results in a single a-Mg phase structure in AZ31B with aluminum as solute in a-Mg phase (Di et al., 2005). Hence, the single a-Mg phase, together with the small grain size and the absence of the $\mathrm{Mg}_{17} \mathrm{Al}_{12}$ phase in the microstructure, could lead to better formability in the twin-roll cast AZ series alloys. 
Notwithstanding the fact that the sheet has better mechanical properties and the process is more economical, only alloys with small solidification ranges can be safely twin-roll cast. Otherwise, failures in the microstructure, e.g. hot cracking and centerline segregation, may occur due to the solidification conditions under rolling pressure. This could be the main drawback of twin-roll casting process that may limit the range of candidate compositions for magnesium sheet. Apart from this, twin-roll casting to produce AZ31 sheet has already experienced significant advances over the past decade. Recently, POSCO and RIST reported the production of AZ31 alloy strips through integration of twin-roll casting and multi-pass coil rolling processes (Jung et al., 2007). The coiled strips were $600 \mathrm{~mm}$ in width with thicknesses of 3-7 mm. However, much wider sheet is required for fabrication of automobile body panels, e.g. engine hood. Thus, one area of focus should be on producing larger sheets by improving twin-roll casting and coiling technologies. Additionally, the capability of twin-roll casting to produce fine dispersed particles should be utilized to develop novel magnesium alloys for sheet. Alloys in which poor formability is attributed to coarse particles, e.g. alloys with high aluminum content, could be potential candidates in this respect.

\section{Thermomechanical processing}

Magnesium sheet is required to undergo various thermomechanical treatments in order to produce various thicknesses and also develop desired mechanical properties for sheet fabrication, especially adequate formability to produce complex profiles. This would also contribute to the properties of the fabricated components, e.g. crashworthiness in automobile body panels. Therefore, it is important to have a thorough knowledge about the evolution of microstructure and viable deformation mechanisms in magnesium. This section will try to highlight the important topics in this area.

\subsection{Recrystallization}

Magnesium does not undergo any solid phase transformation. Consequently, recrystallization is essentially the sole effective mechanism to change the grain morphology in magnesium. Although both dynamic recrystallization (DRX) and static recrystallization (SRX), which occur during and after deformation, respectively, have been studied extensively in cubic metals with low to medium stacking fault energy (e.g. Sakai \& Jonas, 1984; Sakai, 2000), there have been only a limited number of studies on DRX in hcp metals (Ion et al., 1982; Galiyev et al., 2001). Discontinuous recrystallization, characterized by nucleation of bulged or serrated grain boundaries, is known to be a preferred softening mechanism during hot deformation in materials with low to medium stacking fault energy where dynamic recovery is difficult. Although both high and low stacking fault energies have been reported in the literature, magnesium is usually considered to have low stacking fault energy. Therefore, the fact that the discontinuous recrystallization is rarely observed in deformed magnesium, except under high temperature and large straining conditions, has been a puzzle for sometime. Galiyev et al. have proposed a solution to this problem (Galiyev et al., 2003). They noticed that recrystallization always takes place in the area adjacent to the grain boundaries where basal dislocations cross-slip into non-basal planes. As a result, they assumed that splitting width of basal dislocations decreases and non-basal dislocations are formed leading to increased stacking fault energy that will enhance the dislocation rearrangement into cell structures. This assumption is also supported by the calculated values of stacking fault energy for basal and prismatic planes in magnesium, i.e. 78 and 255 
$\mathrm{mJm}^{-2}$, respectively (Galiyev et al., 2003; Sastry et al., 1969; Uesugi et al., 2003 \& Watanabe et al., 2001). Thus, it appears that, although magnesium is generally considered as a low stacking fault energy metal, stacking faults near grain boundaries are mainly associated with non-basal dislocations and, hence, their energy is significantly high. In addition to the stacking fault energy, it has been also indicated that the constraints imposed by the lack of easily activated slip systems have an important effect on the DRX phenomenon in magnesium (Ion et al., 1982).

The kinetics of recrystallization in magnesium alloys is likely a complicated function of deformation temperature, strain, strain rate, deformation mode, grain size, and grain orientation. Therefore, it cannot be described by the usual Avrami equation. Dynamic evolution of new grains in magnesium alloys can be a result of continuous DRX, including twinning DRX and rotation DRX, under cold and warm deformation (Ion et al., 1982 \& Galiyev et al., 2001). In contrast, discontinuous DRX, including the nucleation of new grains and their growth, takes place during deformation at high temperatures. It is well known that the dynamically recrystallized grain size in cubic metals is controlled by deformation condition, i.e. temperature and strain rate, irrespective of the initial grain size (Sakai \& Jonas, 1984; Sakai, 2000). It is found, however, that the dynamically recrystallized grain size in magnesium alloys is clearly dependent not only on deformation conditions, but also on the initial grain size (Kaibyshev et al., 1994; Watanabe et al., 2001).

\subsection{Microstructural evolution}

The as-cast magnesium microstructure can consist of twins parallel to each other within one grain. Such twins can occupy about $12 \%$ of the entire material volume (Kaibyshev \& Sitdikov, 1994). Plastic deformation yields two different structural components, the characteristics and volume fractions depending on strain. At temperatures up to $200^{\circ} \mathrm{C}$, plastic deformation of magnesium produces extensive twinning on multiple systems and formation of dense dislocation pile-ups within initial grains. Multiple twinning in magnesium develops in two systems; a primary $\{10 \overline{1} 2\}<10 \overline{1} 1>$ and a secondary $\{10 \overline{1} 1\}<10 \overline{1} 2>$ (Kaibyshev \& Sitdikov, 1994). The secondary twins occur within coarse lamellae of the primary twins, subdividing them. These crystallites can serve as nuclei and chains of recrystallized grains are evolved at the sites of former twins. This process of microstructural evolution is called twin DRX (TDRX). The second structural component comprises small areas of fine recrystallized grains formed near original boundaries and within original grains at early stages of plastic flow. These grains are smaller than twin grains. These two mechanisms operate simultaneously by further straining and contribute to the evolution of overall microstructure. The fine grains are absorbed by migrating boundaries of recrystallized twin grains, and repetitive DRX occurs within the twin grains (recrystallized grains evolved inside twins) and results in the formation of new smaller grains (Kaibyshev \& Sitdikov, 1995a; Kaibyshev \& Sitdikov, 1995b). This type of microstructural evolution is inherent in the cool deformation range of magnesium.

At intermediate temperatures, i.e. $300^{\circ} \mathrm{C}$, deformation twinning on multiple systems results in an increase in the volume fraction of twins. Figure 1 illustrates a twin morphology developed in an AZ31 alloy after $\varepsilon=0.3$ rolling deformation at $300^{\circ} \mathrm{C}$. The formation of secondary twins within lamellae of primary twins plays an important role in TDRX at this temperature, Figure 1. It has been proposed that TDRX mechanism comprises three 
sequential stages (Sitdikov et al., 2003). Firstly, nucleation occurs by either intersection of various systems of twins or rearrangement of lattice dislocations within the twin lamellae. At the second stage, twin boundaries are changed into random high angle boundaries due to formation of orientation misfit dislocations. As a result, the nuclei are transformed into recrystallized grains, which have non-equilibrium shape close to tetragonal one. At the third stage, migration of their boundaries begins to occur. This also indicates that the size of recrystallized grains is determined by the width of twin lamellae, as also shown in Figure 1. Such a multi-stage character of the microstructure evolution is a common feature of TDRX operating over a wide range of temperatures. Regarding the second structural component, by increasing the strain, subboundaries reorient and convert into high angle boundaries. This has been seen along the original boundaries as well as near some former twin boundaries and contributes to the evolution of grain morphology (Galiyev et al., 2003). Since the growth of these grains is not limited to the width of twins, they can grow freely and, as a result, the mean grain size increases. This microstructural evolution and such an effect of strain on the recrystallized grain size usually take place in the temperature range of 250$350^{\circ} \mathrm{C}$, which can be regarded as the range of warm plastic deformation in magnesium.
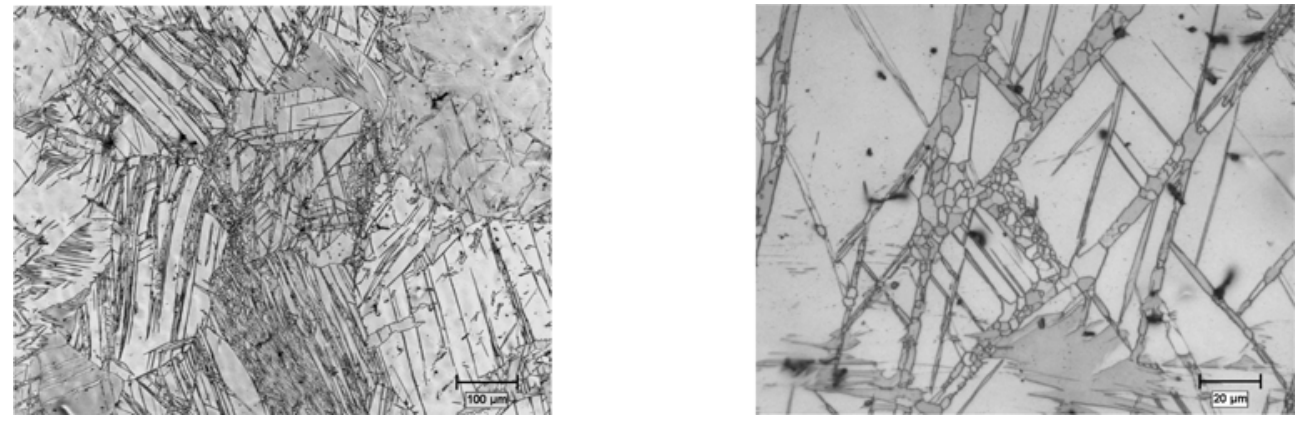

Fig. 1. Development of twins and recrystallization in an AZ31 alloy due to $\varepsilon=0.3$ rolling deformation at $300^{\circ} \mathrm{C}$. (Original structure was as-cast and twin-free.)

As the deformation temperature approaches $450^{\circ} \mathrm{C}$, twins become less prominent. Instead, nucleation of new grains in the vicinity of grain boundaries, so-called necklacing, plays a more important role in the evolution of microstructure, Figure 2. The formation of recrystallized grain chains evolved by continuous DRX occurs along both the initial grain boundaries and the boundaries of twin grains. However, the former begins to occur at lower strains and the rate of this process is faster than that along prior twin grain boundaries. Discontinuous DRX is also expected to contribute at large strains in this thermal regime.

In summary, there are different DRX mechanisms in magnesium; their extents of operation depend on strain and temperature. Because the growth of nuclei is affected by these DRX mechanisms, e.g. nucleation at grain boundaries and within twins, the mean grain size can increase or decrease with straining. This contradicts the normal rule of recrystallization in cubic metals, i.e. there is no strain effect on recrystallized grain size during DRX. Such dependency of grain size on temperature and strain with regard to underlying DRX mechanisms is illustrated in Figure 3 for pure magnesium (Sitdikov \& Kaibyshev, 2001). It should be noted that the operation of DRX mechanisms and the evolution of grain size is also affected by alloying elements as these can change the stacking fault energy and mobility 


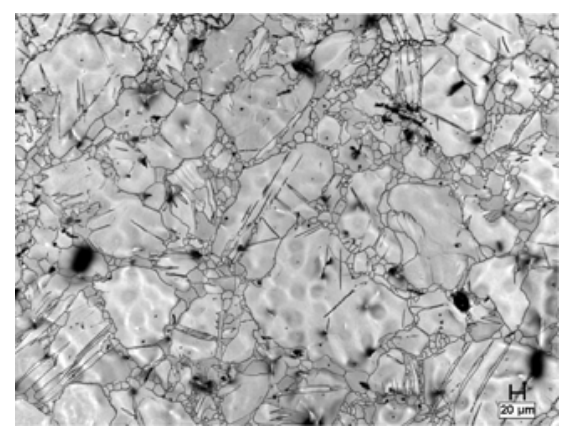

Fig. 2. Necklacing recrystallization in an AZ31 alloy due to $\varepsilon=0.3$ rolling deformation at $450^{\circ} \mathrm{C}$. (Original structure was as-cast and twin-free.)
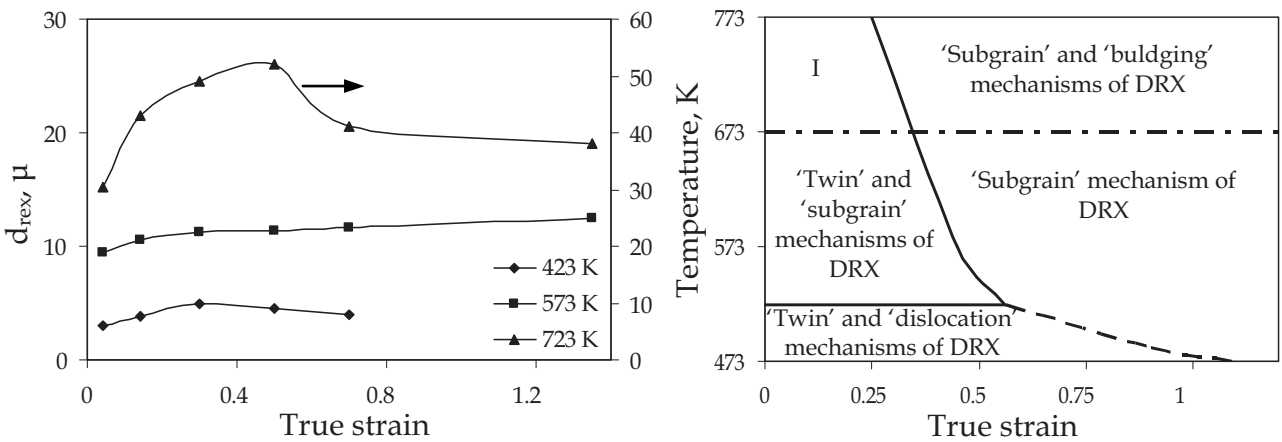

Fig. 3. Strain and temperature dependence of average recrystallized grain size in pure magnesium (left), and corresponding recrystallization mechanisms (right) (region ' $I$ ' represents the area where initial twins transform into recrystallized grains during deformation) (Sitdikov \& Kaibyshev, 2001).

of boundaries. For instance, it has been shown that the final grain size after extrusion at $350^{\circ} \mathrm{C}$ is larger than the initial grain size in pure magnesium, but not in W0 alloy (yttriumcontaining magnesium) (Cottam et al., 2006).

The fact that the dominant mechanism of DRX changes by temperature and strain suggests that there are different operating deformation and shear mechanisms; their activities depend on both temperature and strain. This is because a specific mechanism of plastic deformation can result in a certain type of DRX mechanism. The deformation mechanisms in magnesium will be explained in more detail later.

\section{Formability}

The lack of adequate number of slip systems to accommodate overall strain is considered as the principal reason for poor formability of magnesium. Therefore, in order to advance applications of magnesium sheet to structural components, especially in automobile and aerospace industries, enhancement of formability has been the main focus in numerous investigations. Grain refinement is proving to be an effective approach for this purpose. Moreover, prevention and retardation of basal texture development during deformation 
positively affects magnesium formability, as this results in participation of more slip systems in deformation and postpones failure to larger strains. These are discussed in the following section.

\subsection{Effect of grain size}

Early studies on the deformation mechanisms in magnesium single crystals, which were focused on slip system analysis, revealed that deformation at room temperature occurs by slip on the basal plane in $<11 \overline{2} 0>$ direction. Non-basal slip was regarded as a high temperature slip system, i.e. $>200^{\circ} \mathrm{C}$, (Wonsiewiczs \& Backofen, 1967). Later, $\langle a\rangle$ and $\langle c+a\rangle$ non-basal slip systems were also confirmed to be active at room temperature (Stohr \& Poirier, 1972; Obara, 1973). However, the behavior of magnesium polycrystal is very different than that of the single crystal, due to the strong grain size dependency. In general, high ductility and low strain hardening rates are observed over a wide range of temperature in single crystals, whereas polycrystalline magnesium display low ductility (5-20\%) and high strain hardening rates at room temperature. The restriction of magnesium to a grain size of $1 \mathrm{~mm}$ increases both the yield strength and the strain hardening rate by factor of $>10$ and $>10^{3}$, respectively, while reduces the fracture strain tenfold, all compared with those of single crystal (Roberts, 1964; Wonsiewiczs \& Backofen, 1967). Such characteristics are very different from those in cubic metals, where single crystals and polycrystals are not greatly dissimilar. The reason for this is ascribed to the only two independent easy slip systems in magnesium, both involving the $1 / 3<11 \overline{2} 0>$ or $\langle a\rangle$ dislocations on the basal plane. Hence, the $h c p$ structure of magnesium does not satisfy the well-known Taylor criterion requiring five independent easy slip systems for homogenous ductility of a polycrystalline aggregate (Taylor, 1938). In other words, each grain should satisfy the Taylor criterion in order to accommodate an applied strain.

However, in order to be used for the structural components, magnesium should exhibit sufficient ductility not only at static but also at dynamic strain rates, because components are often fractured by shear or tensile forces under dynamic loading. This has inspired numerous investigations on the enhancement of ductility in magnesium alloys. Figure 4 suggests that grain refinement is a promising approach to improve ductility at both quasistatic and dynamic strain rates, as shown in both pure magnesium and ZK60 (zirconiumcontaining magnesium) (Mukai et al., 2003). When grains are coarse, cracking along twin boundaries and grain boundaries is encouraged. Upon straining, the cracks propagate and coalesce leading to eventual failure. On the other hand, when grains are small, twins are less prominent and they are also smaller, hence, failure is delayed (Mukai et al., 2003). This example clearly denotes the importance of twins as an embrittling mechanism in magnesium. A similar improvement in ductility, even at a dynamic strain rate of $\sim 2 \times 10^{3} \mathrm{~s}^{-1}$, was observed in WE43 alloy (magnesium alloyed with yttrium and rare earth elements) by refining the grain size (Mukai et al., 1998).

Another effect of grain refinement is on the slip systems. Although slip on basal planes is the easiest at room temperature as compared with slip on prismatic and pyramidal planes, non-basal dislocation activities and cross slip from basal to non-basal planes have been observed to take place in fine grains, e.g. $6 \mu \mathrm{m}$, AZ31 alloy (Koike et al., 2003). The CRSS ratio, $\tau_{\text {prismatic }} / \tau_{\text {basal, }}$ estimated in this case was 1.1 which is much lower than the values (about 100) reported in single crystal magnesium. A study of the effect of grain size on 


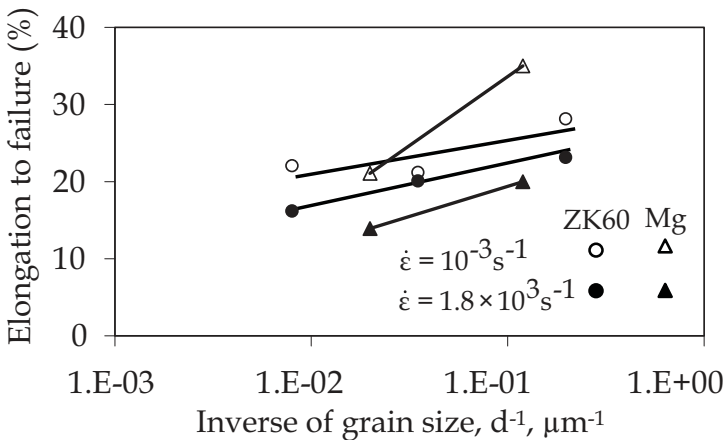

Fig. 4. Variation of elongation to failure at room temperature versus inverse of grain size in pure magnesium and ZK60 alloy (zirconium-containing magnesium) (Mukai et al., 2003).

dislocation activities at room temperature in two AZ31 alloys, one with a grain size of $50 \mu \mathrm{m}$ and the other with $7 \mu \mathrm{m}$, revealed that in the coarse grain alloy, non-basal $\langle a\rangle$ dislocations were active near the grain boundaries while basal $\langle a\rangle$ dislocations were dominant in the grain interior ( $\tau_{\text {non-basal }} / \tau_{\text {basal }} \approx 15.4$ ). On the other hand, at $7 \mu \mathrm{m}$ grain size, non-basal $\langle a\rangle$ dislocations were active in all regions ( $\tau_{\text {non-basal }} / \tau_{\text {basal }} \approx 0.88$ ). The density of non-basal $\langle a\rangle$ dislocation segments was found to be $40 \%$ of the total dislocation density (Kobayashi et al., 2003). Such activation for non-basal dislocations can be ascribed to the stresses induced to maintain grain boundary compatibility. In large grains, this effect is limited at grain boundary regions whereas it is all over grains in fine grains.

Furthermore, grain size influences twinning, the activation of which leads to distinctive features in the temperature sensitivity of yield stress. The $\{10 \overline{1} 2\}$ extension twin is the most common type in magnesium, and is favored when compressive stresses are applied parallel to the basal planes. This twin is also the source of the large difference between compressive and tensile behaviors of magnesium. Such anisotropy diminishes by increasing temperature and disappears at a certain temperature where tensile and compressive yield stresses coincide. It is believed that, at this temperature, the stress required to activate $\{10 \overline{1} 2\}$ twinning equals that required to activate second order pyramidal $\langle c+a\rangle$ slip (Barnett, 2003). These two systems are the only systems accommodating deformation along the $c$-axis direction of the $h c p$ crystal. The CRSS for $\langle c+a\rangle$ slip is high at room temperature and decreases rapidly with increasing temperature, whereas that for twinning is expected to be relatively temperature insensitive. On the other hand, the twinning stress increases with decreasing grain size more rapidly than the stress required to activate slip (Meyers et al., 2001). As a result, the slope of the Hall-Petch relationship, $k$, is usually greater for twinningdominated flow than that for slip-dominated flow. In this respect, decreasing the grain size is similar to increasing temperature in that slip is favored over twinning. As an example, Figure 5 clearly demonstrates the effect of grain size on compressive flow behavior in an AZ31 alloy. There are two classes of flow behavior. The material flows along a concave path when twins are active. This appears to be the case for grain sizes of $16 \mu \mathrm{m}$ down to $8 \mu \mathrm{m}$, with a gradual decrease in the activity of twins by decreasing the grain size. On the other hand, the material exhibits a conventional flow behavior at grain sizes $\leq 4 \mu \mathrm{m}$, where twinning is difficult. This indicates that grain refinement can be a strategy to improve 
formability where twins act as an embrittling mechanism, i.e. at low temperatures. In contrast to cubic metals, Figure 5 shows that the rate of strain hardening is greater at larger grain size. This phenomenon is ascribed to the interaction between twins and dislocations, rather than to the stress required for twinning. Nevertheless, hardening due to texture development as well as softening mechanisms common in fine grain materials, e.g. recrystallization and grain boundary sliding, should also be taken into account.

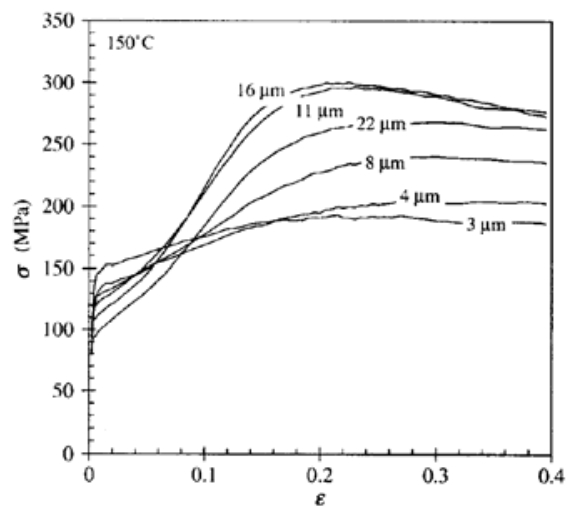

Fig. 5. Compressive true stress-strain curves obtained at $0.01 \mathrm{~s}^{-1}$ and $150^{\circ} \mathrm{C}$ at various grain sizes, AZ31 alloy, (Barnett et al., 2004).

Consequently, it is reasonable to expect a critical grain size for transition from twinning to slip dominated flow. Obviously, this grain size depends on both temperature and strain rate. Barnett et al. proposed that the correlation of such critical grain size $\left(d_{c}\right)$ in AZ31 with temperature and strain rate in compression can be described as (Barnett et al., 2004);

$$
d_{c}=\left(\frac{0.15 \ln Z-12.2}{73-3.8 \ln Z}\right)^{2}
$$

where $Z$ is the Zener-Hollomon parameter $(Z=\dot{\varepsilon} \exp (Q / R T)), \dot{\varepsilon}$ is strain rate, $\mathrm{Q}$ is deformation activation energy, $\mathrm{R}$ is gas constant $(8.314 \mathrm{~J} / \mathrm{molK})$, and $\mathrm{T}$ is absolute temperature in Kelvin.

In contrast to the compression flow behavior and similar to cubic metals, the tensile flow behavior follows the Hall-Petch law in terms of the effect of grain size, Figure 6. In tension, if the direction of the applied stress is parallel to the basal planes, activation of $\{10 \overline{1} 2\}$ twins is difficult. Instead, the $\{10 \overline{1} 1\}$ contraction twin, which accommodates contractions along the $c$-axis, and the $\{10 \overline{1} 1\}-\{10 \overline{1} 2\}$ double twin operate in tension (Jiang, 2008). But, unlike the $\{10 \overline{1} 2\}$ twin, these twins do not spread over the whole microstructure even at high strains, e.g. 0.15 , as they have much higher CRSS values. Nevertheless, the effect of grain size on $k$ is similar to that in compression, in that decreasing the grain size lowers the strain hardening rate, Figure 6.

It is well known that high formability is usually associated with very low strain rates and high temperatures. However, it is always desirable to apply large amounts of deformation at high strain rates and low temperatures. Low strain rates limit the speed of forming 


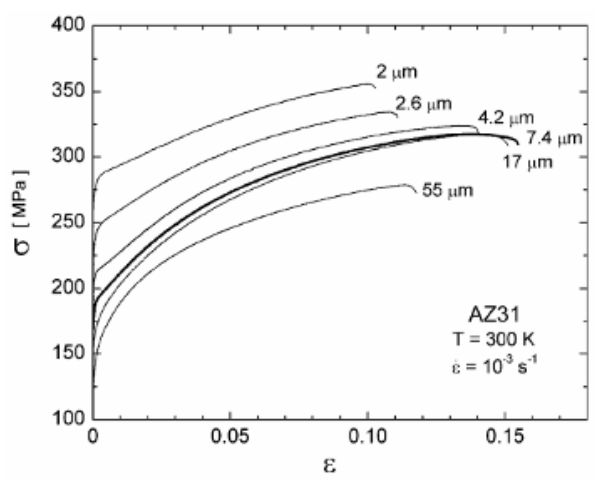

Fig. 6. Tensile true stress-strain curves of AZ31 alloy (rolled and annealed) at various grain sizes (Valle et al., 2006).

processes, and materials which do not display good formability at high strain rates tend to have inferior dynamic fracture properties, as well. Elevated temperature deformation, on the other hand, incurs increased energy costs and the possibility of surface oxidation. In addition, selective depletion of alloying elements on the surface is prevalent at high temperatures. Grain refinement has proved to be an effective strategy to alleviate these constrains. For instance, by decreasing the grain size from 10 to $2.5 \mu \mathrm{m}$ in a ZK60 alloy, the superplastic strain rate increased by about 100 times, yet at a lower temperature (Watanabe $\&$ Mukai, 1999). This indicates that both high strain rate superplasticity and superplasticity at low temperatures in magnesium alloys can be achieved by decreasing the grain size.

It is difficult to obtain fine grain size in commercial magnesium alloys. In sheet production, the rolling temperature must be high to avoid edge and surface cracking, especially in high aluminum content alloys. Such high temperatures accelerate the growth of fine recrystallized grains. Therefore, complicated thermomechanical schedules incorporating frequent interpass reheating processes should be employed to gradually refine the grain size, which adds to the production cost. This barrier has led to investigations into the superplasticity in coarse grain alloys. In one study, an AZ61 (Mg-6wt\%Al-1wt\%Zn) alloy with a grain size of $16 \mu \mathrm{m}$ displayed $950 \%$ elongation-to-fracture at strain rate of $10^{-3} \mathrm{~s}^{-1}$ and temperature of $400^{\circ} \mathrm{C}$ (Kim et al., 2001). Such a large elongation before rupture at high strain rates is noteworthy when compared with the smaller elongation of some other magnesium alloys, including AZ61 itself, with finer grains. Microstructural examination revealed cavity formation at grain boundaries and the occurrence of dynamic recrystallization followed by grain growth. However, no clear explanation has yet been offered on how dynamic recrystallization and grain growth contributes to the elongation, although the former clearly reduces applied stress and the latter reduces the stored energy. More study is required to understand the mechanisms responsible for superplasticity in coarse grain alloys.

\subsection{Effect of texture}

Formability of magnesium is strongly affected by orientation of the basal plane. This dependency of magnesium on crystal orientation is much more important than that of cubic metals since the former has limited number of slip systems and is very susceptible to twinning that readily orients basal planes. In addition to basal slip, which is the easiest slip 
system, prismatic slip has been found to be of crucial importance during high temperature superplasticity. This was confirmed by more than $600 \%$ elongation at $300{ }^{\circ} \mathrm{C}$ and $4.2 \times 10^{-4} \mathrm{~s}^{-1}$ in a single crystal in which prismatic slip was the only active slip system, crystal I in Figure 7. At an orientation where prismatic slip is difficult (crystal II in Figure 7), the elongation was $430 \%$ under similar condition. Surprisingly, increasing the deformation temperature deteriorated the formability in both crystals. In this case, DRX and grain boundary cracking are the reasons for embrittlement; probably by introducing grains with different orientations where prismatic slip is difficult and regions that are susceptible to cracking, i.e. grain boundaries. Figure 7 also demonstrates that flow behavior strongly depends on crystal orientation. Crystal I strain hardens gradually during activation of a single prismatic plane and then the rate of strain hardening increases rapidly when the strain-induced crystal orientation places a second prismatic slip plane in a favored orientation and cross slip occurs. In contrast, crystal II exhibits conventional flow behavior, i.e. gradual decrease in the strain hardening rate followed by softening, in absence of the prismatic slip.

There is a similar effect in polycrystalline magnesium. Figure 8 shows the flow behavior of two textured AZ31 alloys, one pulled parallel to the basal planes and the other at an angle of $\sim 45$ degrees with the basal planes. Specimen II has a lower yield stress and exhibits a remarkable strain hardening and a large elongation at a relatively high strain rate, with a UTS almost equal to that of specimen I. In contrast, specimen I displays brittle behavior; a minor strain hardening followed by failure.

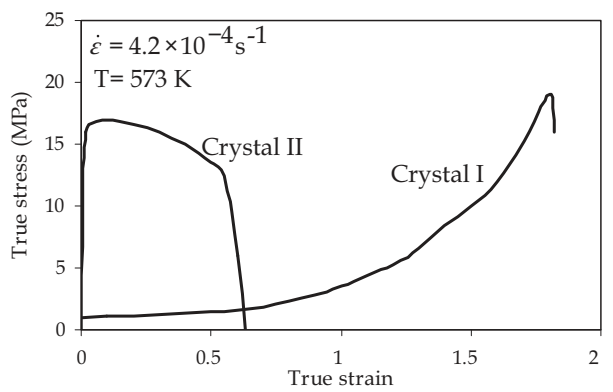

Fig. 7. Tensile deformation of magnesium single crystals; easy prismatic slip (crystal I) and difficult prismatic slip (crystal II) (Miura et al., 2005).

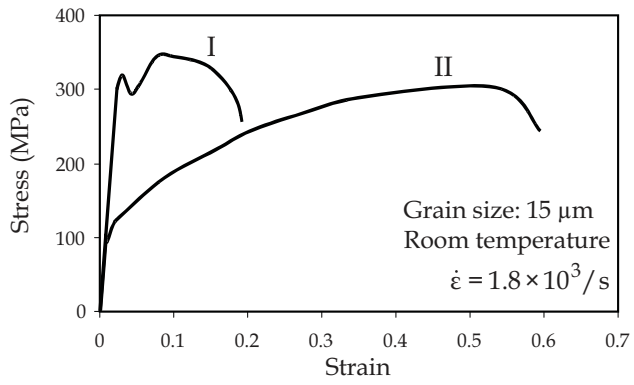

Fig. 8. Effect of crystallographic orientation on tensile flow curve in AZ31 alloy (Mukai et al., 2003). (Stress direction parallel to basal planes (I), and at 45 degrees with basal planes (II)) 
Generally, magnesium exhibits very poor formability when it is deformed parallel to basal planes, i.e. the direction of applied stress is perpendicular to the $c$-axis, as there are only two $<a>$ non-basal independent slip systems that can be active under this condition. During sheet production, basal planes are readily oriented toward the sheet surface in early stages of rolling. This leads to the development of a basal texture parallel to the sheet surface. In the fabrication process, the sheet is stretched parallel to the basal planes and, therefore, as specimen I in Figure 8 shows, the amount of deformation it can tolerate before rupture is very limited. This suggests that alleviation of basal texture is an effective method to improve the formability of magnesium sheet. One possible strategy is to develop new alloys which are less prone to the basal texture. Alloys containing rare earth elements and yttrium have been the main focus in this respect (Senn \& Agnew, 2008). However, this approach may not always be attractive economically. Furthermore, it may introduce new technical difficulties in the sheet production process, especially in the twin-roll casting. Therefore, alloys based on the AZ series constitute the main body of research in this area. Very recently, it was shown that the basal texture of AZ31 sheet, produced by twin-roll casting, can be weakened by controlled thermomechanical treatment (Masoumi et al., 2010b). The microstructure of twin-roll cast AZ31 comprises large columnar grains and densely distributed secondaryphase particles, Figure 9. Additionally, due to the rolling deformation which occurs as the solidified strip goes through the twin rolls, it exhibits a strong basal texture, as shown by the pole figure in Figure 9. When annealed at $420^{\circ} \mathrm{C}$, as expected, the second phases were dissolved in the matrix and columnar grains were replaced with fine grains owing to recrystallization. But, the most important change happened in the sheet texture; the basal texture was weakened noticeably, Figure 10. The substructure in the as-twin-roll cast sheet revealed a high concentration of dislocations at the secondary-phase particles. Therefore, the texture alteration was attributed to the particle-stimulated nucleation (PSN) mechanism of recrystallization that resulted in the formation of grains with random orientations, Figure 10. A similar treatment was applied to a conventionally produced AZ31-H24 sheet and also a DC cast and cold-rolled plate. However, neither of them showed any change in its initial basal texture, Figure 11. These observations indicate the advantage of the rapid cooling associated with the twin-roll casting process; generating a large fraction and uniform distribution of fine secondary-phase particles. Preliminary evaluation of mechanical properties at room temperature also proved the beneficial effect of such texture alteration, as compared to the as-twin-roll cast AZ31 sheet (Masoumi et al., 2010a).
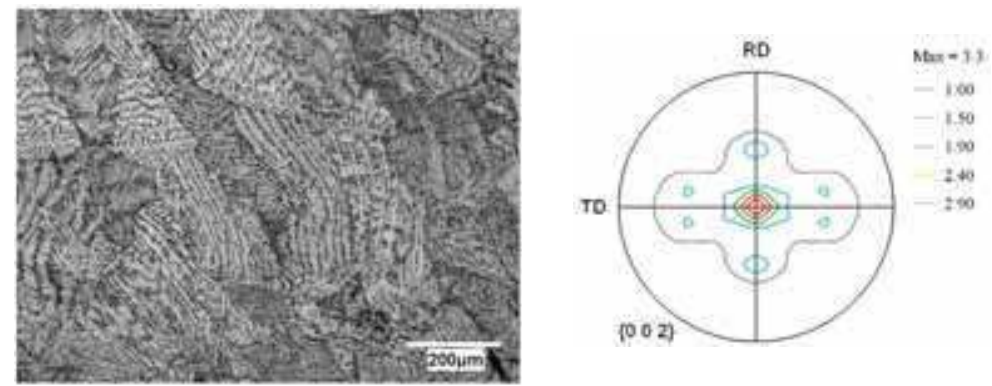

Fig. 9. Thickness microstructure of twin-roll cast AZ31 sheet and basal plane pole figure (Masoumi et al., 2010b). RD and TD are rolling and transverse directions of the sheet, respectively. 

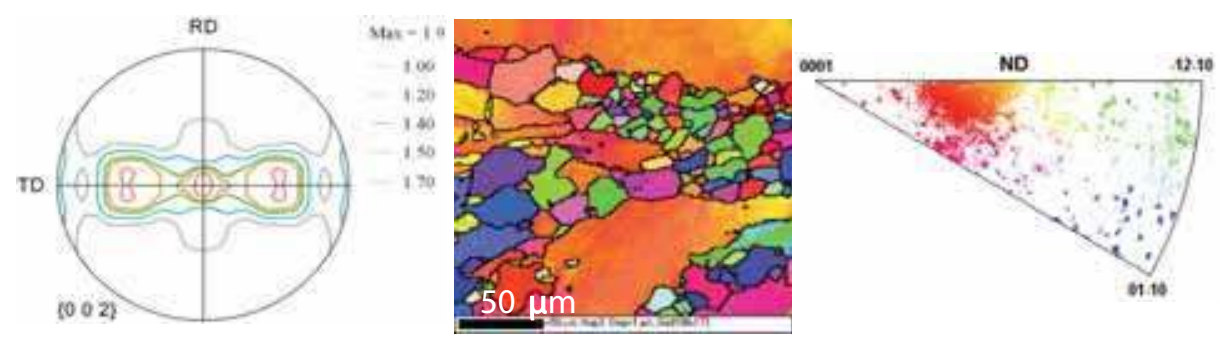

Fig. 10. Basal plane pole figure of twin-roll cast AZ31 sheet and orientation map of recrystallized grains in the plane of $\mathrm{RD}-\mathrm{TD}$, both after annealing at $420^{\circ} \mathrm{C}$ (Masoumi et al., 2010b). RD, TD, and ND are rolling, transverse, and normal directions of the sheet, respectively.
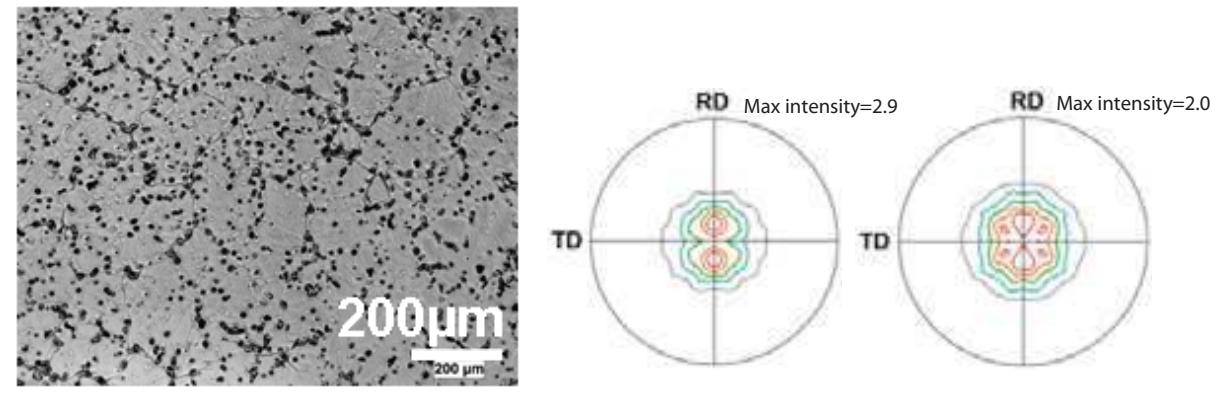

Fig. 11. DC AZ31 as-cast microstructure and $\{002\}$ pole figures after $15 \%$ cold rolling (left) followed by annealing at $420^{\circ} \mathrm{C}$ (right). (Masoumi et al., 2010b). RD and TD are rolling and transverse directions, respectively.

\section{Deformation behavior at elevated temperatures}

By increasing temperatures, while the effect of twinning diminishes, concurrent operations of basal and non-basal slip systems are conducive to improved formability. On the other hand, as the deformation temperature increases, the formability becomes more dependent on the deformation rate, which often has an opposite effect to that of temperature. Since, in practice, it is desired to increase the productivity by increasing the deformation rate and, at the same time, keep the deformation temperature low for economy and surface quality, an optimum combination of temperature and strain rate is required to achieve an adequate formability in a given sheet material. This demands a thorough understanding of viable deformation mechanisms at various temperatures and strain rates, which are also affected by the alloying elements in the magnesium sheet. Essentially, this would lead to the development of constitutive models of plasticity capable of predicting flow behavior during sheet forming.

The combined additions of aluminum and zinc to magnesium yield an optimum combination of strength and ductility, in addition to increased corrosion resistance. This has promoted the AZ series alloys to the top in the list of magnesium sheet alloys. Al and $\mathrm{Zn}$ improve mechanical properties both by solid solution strengthening and secondary-phase 
precipitation. Upon aging, the equilibrium phase $\mathrm{Mg}_{17} \mathrm{Al}_{12}$ precipitates from the supersaturated solid solution, affecting metal deformation and properties. At high $\mathrm{Al}$ contents, precipitation of coarse $\mathrm{Mg}_{17} \mathrm{Al}_{12}$ at grain boundaries deteriorates the formability of the alloy, especially during rolling. Hence, alloys for sheet production usually contain less than $6 \mathrm{wt} \% \mathrm{Al}$. However, this may not be as much a problem with twin-roll casting where rolling deformation is limited. Manganese is also added to the AZ alloys primarily to improve corrosion resistance, and also to refine the as-cast grain size. Therefore, its possible effect on deformation behavior of the AZ series alloy, especially in the sheet form, has rarely been studied. A recent study, while reconfirming the detrimental effect of $6 \mathrm{wt} \% \mathrm{Al}$ to the hot rollability of AZ series magnesium sheet, showed that addition of Mn from 0.06 to $0.24 \mathrm{wt} \%$ counteracts such effect and improves hot rollability (Zarandi et al., 2008).

Commonly, three tensile flow characteristics can be expected from the sheet of AZ series at various combinations of elevated temperature and strain rate, Figure 12. At high $Z$ value, e.g. $300^{\circ} \mathrm{C}$ and $0.1 \mathrm{~s}^{-1}$, the rate of strain hardening is initially high but decreases rapidly with strain, leading to an early onset of flow softening and a low failure strain. On the other hand, at $450^{\circ} \mathrm{C}$ and $0.0003 \mathrm{~s}^{-1}$, where $Z$ is low, the initial flow stress is very low and the material strain hardens at a low rate, but to a high fracture strain. The material exhibits an intermediate flow behavior at $400{ }^{\circ} \mathrm{C}$ and $0.1 \mathrm{~s}^{-1}$, but the appearance of a 'hump' makes it distinct enough to merit a separate identity. Such a flow behavior is opposite of what is usually expected when the peak stress is associated with geometric instability, i.e. necking. Instead, it is reminiscent of the steady-state region commonly observed in compression flow curves after dynamic recrystallization has taken place. This was confirmed to be the reason for the flow behaviour at $400^{\circ} \mathrm{C}$ and $0.1 \mathrm{~s}^{-1}$ in Figure 12, as well (Zarandi et al., 2008).

The different effect of $\mathrm{Mn}$ in each regime is also noticeable in Figure 12. It has been found that, above $400^{\circ} \mathrm{C}$ and below $0.001 \mathrm{~s}^{-1}$, the higher Mn content results in an almost linear strain hardening behavior toward UTS. Examples of this are the flow curves at $0.0003 \mathrm{~s}^{-1}$ in Figure 12. Such linearity corresponds to increased strain-to-fracture (Zarandi et al., 2008). This is also consistent with the aforementioned beneficial effect of $\mathrm{Mn}$ on the sheet rollability. Figure 13 demonstrates a summary of how composition and strain rate can affect formability, as represented by elongation-to-fracture, in the AZ series sheets. As expected, the elongation increases with decreasing strain rate, with its maximum value at $4 \mathrm{wt} \% \mathrm{Al}$ at all strain rates, except at $0.0003 \mathrm{~s}^{-1}$ where it is slightly higher at $6 \mathrm{wt} \% \mathrm{Al}$ and the higher $\mathrm{Mn}$ content. It is interesting to note that the beneficial effect of $\mathrm{Mn}$ is most pronounced at the highest $\mathrm{Al}$ content. Even though this can partly be attributed to the grain refinement effect of $\mathrm{Mn}, \mathrm{Mn}$ might have interacted with $\mathrm{Al}$, reducing the density of detrimental coarse $\mathrm{Mg}_{17} \mathrm{Al}_{12}$ particles.

The occurrence of all these variations reflects the operation of different deformation mechanisms controlling flow behavior in different regimes. Strain-rate-change testing is commonly performed to study dominant deformation mechanisms at elevated temperatures. Typical result of such test is the plot of logarithm of strain rate versus logarithm of flow stress. This is shown in Figure 14 at three different temperatures and for two AZ61 series sheets containing two different levels of Mn.

The strain-rate sensitivity of flow stress, $\mathrm{m}=\partial \ln \sigma / \partial \ln \dot{\varepsilon}$, is dependent upon active deformation mechanisms and, therefore, an indication of underlying deformation mechanisms. The slope of $\ln \dot{\varepsilon}-\ln \sigma$ plot represents the stress exponent, $n$ (or $1 / m$ ), in the constitutive equation: 


$$
\dot{\varepsilon}=A D\left(\frac{b}{d}\right)^{p}\left(\frac{\sigma}{E}\right)^{n}
$$

where $\dot{\varepsilon}$ is the true strain rate, $A$ is a constant, $D=D_{0} \exp (-Q / R T)$ is diffusion coefficient, $b$ is the Burgers vector, $d$ is the grain size, $n$ is the stress exponent, $\sigma$ is the true stress, $E$ is the temperature-dependent Young's modulus, $p$ is the grain size exponent, and $Q$ is the activation energy for diffusion. As Figure 14 indicates, $n$ is equal to 6 at high $Z$ values, which here comprise high strain rates at all three temperatures. This high $n$ value is often associated with dislocation slip creep where the deformation rate is controlled by dislocation climb (De La Torr et al., 1991). At low $Z$ values; low strain rates and high temperatures, $n$ approaches values of $\leq 2$. In this condition, grain boundary sliding prevails as the dominant deformation mechanism (Del Valle et al., 2005). Therefore, the large elongationto-fracture values associated with low strain rates in Figure 13 is the result of grain boundary sliding as the dominant deformation mechanism. It is also noted that the addition of $\mathrm{Mn}$ reduces the $n$ value and increases the strain rate where $n$ changes to lower values at $400^{\circ} \mathrm{C}$ and

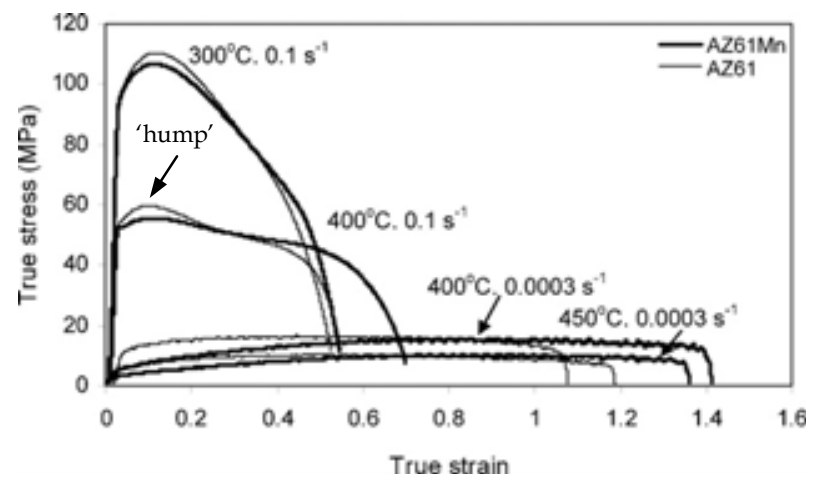

Fig. 12. Flow characteristics of two AZ61 sheets; AZ61 with 0.06wt\%Mn and AZ61Mn with $0.24 \mathrm{wt} \% \mathrm{Mn}$, in various conditions (Zarandi et al., 2008).



Fig. 13. Effect of $\mathrm{Al}$ and $\mathrm{Mn}$ on elongation-to-fracture at $450^{\circ} \mathrm{C}$ at various strain rates (Zarandi et al., 2008). Each data point is an average of four samples. 


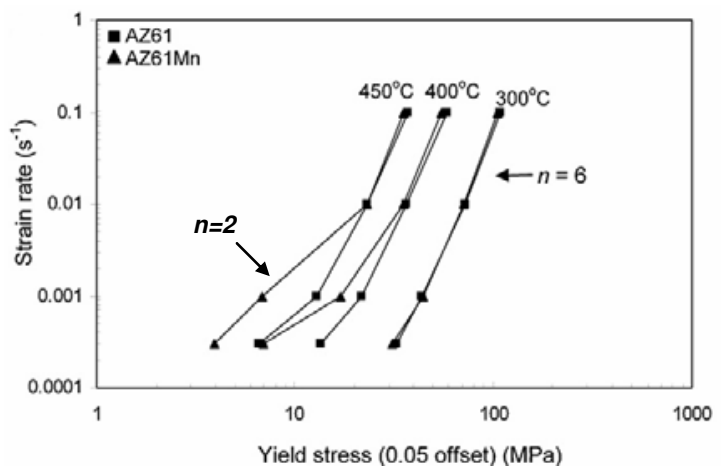

Fig. 14. Plots of strain rate versus yield stress of two AZ61 sheets; AZ61 with $0.06 \mathrm{wt} \% \mathrm{Mn}$ and AZ61Mn with 0.24wt\%Mn (Zarandi et al., 2008).

$450^{\circ} \mathrm{C}$, Figure 14 . In other words, Mn enhances contribution of grain boundary sliding and extends its operation to higher strain rates. Again, such an effect can be due to the grain refinement effect of $\mathrm{Mn}$ as this favors grain boundary sliding. This is why the alloys containing higher level of Mn tend to display larger elongations-to-fracture in Figure 13. Grain boundary sliding often leads to a uniform elongation, also known as diffuse necking, in the tested specimen. The absence of localized deformation allows the material to undergo more strain before failure. Dislocation slip creep, on the other hand, results in a localized deformation, known as necking, and an early fracture (Vespa et al., 2008).

It has been shown that grain boundary sliding in magnesium operates simultaneously with crystallographic slip (Del Valle et al., 2005). Due to low strain rates, the material resides at high temperature for a relatively long time during deformation. This, together with the stimulating effect of strain on grain boundary migration, leads to a dynamic grain growth, i.e. grain growth during deformation. The grain growth would hinder grain boundary sliding and, therefore, lattice slip takes over the deformation in large grains. It could be expected that the lattice slip would eventually trigger dynamic recrystallization in large grains, which in turn, promotes grain boundary sliding. In other words, deformation at low $Z$ values can be a result of sequential operation of grain boundary sliding-crystallographic
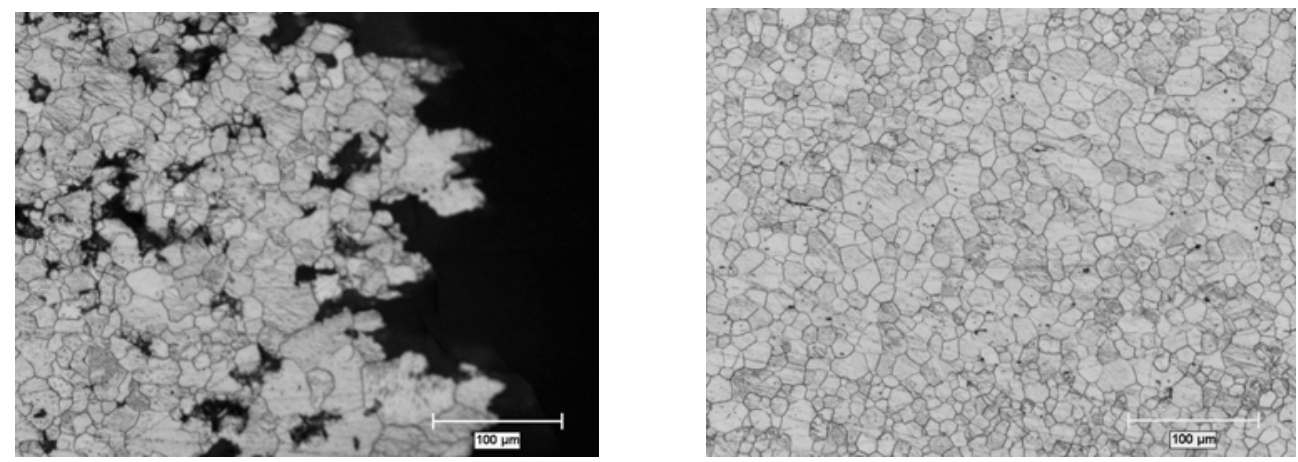

Fig. 15. Microstructures of an AZ41 alloy deformed at $400^{\circ} \mathrm{C}$ and $0.0003 \mathrm{~s}^{-1}(n=2)$; fracture tip (left) and out-of-gage region (right) (Zarandi et al., 2008). 
slip-dynamic recrystallization. Eventually, the peak stress is reached and followed by a relatively shorter flow softening region, Figure 12, which is mainly a consequence of growth and coalescence of cavities at grain boundaries. A typical fractured microstructure resulting from grain boundary sliding is shown in Figure 15. For comparison, the microstructure of the out-of-gage region, i.e. unstrained microstructure, is also shown. The smaller grain size in the out-of-gage region denotes the strain-induced grain growth in the gage region.

With regard to the above discussion, it is well acknowledged that a fine grain structure is desired in sheet microstructures. To achieve this, it is required to properly design rolling schedules. Figure 16 illustrates two examples of the effect of rolling temperature. The result of rolling at $350^{\circ} \mathrm{C}$ is fine recrystallized grains surrounding unrecrystallized 'pancaked' material; twins are distributed throughout, and the structure is heterogeneous and 'banded'. The material rolled at $450^{\circ} \mathrm{C}$, has a coarser grain size and appears to be more recrystallized, as indicated by less banding and only a few remnants of pancaked grains, although some twins are evident (it should be noted that some twins form after rolling and are the result of unloading the sheet). When tested in tension at $450^{\circ} \mathrm{C}$ and $0.001 \mathrm{~s}^{-1}$, Figure 17, the partially recrystallized structure (rolled at $350^{\circ} \mathrm{C}$ ) exhibited $35 \%$ larger elongation-to-fracture than the coarser grain microstructure (rolled at $450^{\circ} \mathrm{C}$ ). By increasing the test temperature to $450^{\circ} \mathrm{C}$, recrystallization by nucleation of new fine grains commences throughout in the former, while grain growth, rather than nucleation, prevails as a result of heating in the latter. Therefore, owing to the smaller grains, there is more contribution from grain boundary sliding to the accommodation of strain in the former leading to a larger elongation before failure. An opposite result is observed when the strain rate is increased to $0.1 \mathrm{~s}^{-1}$; the former shows $60 \%$ smaller elongation-to-fracture than the latter, Figure 17. Examination of microstructures after fracture revealed a bimodal microstructure; large grains surrounded by small grains, in the former with cracks running along the large grains. This was suggested as the cause of ductility loss. The latter exhibited a rather uniform large grain size (Vespa et al., 2008).

A study of the effect of rolling parameters has suggested that rolling temperature and strain are of particular significance in controlling the sheet microstructure. In contrast, rolling speed and reheat time appeared less influential (Vespa et al., 2008). In that study, the maximum rolling speed was $24 \mathrm{~m} / \mathrm{min}$. However, it has been shown that increasing the rolling speed to very high rates; i.e. $2000 \mathrm{~m} / \mathrm{min}$, at $200^{\circ} \mathrm{C}$ leads to a very fine recrystallized
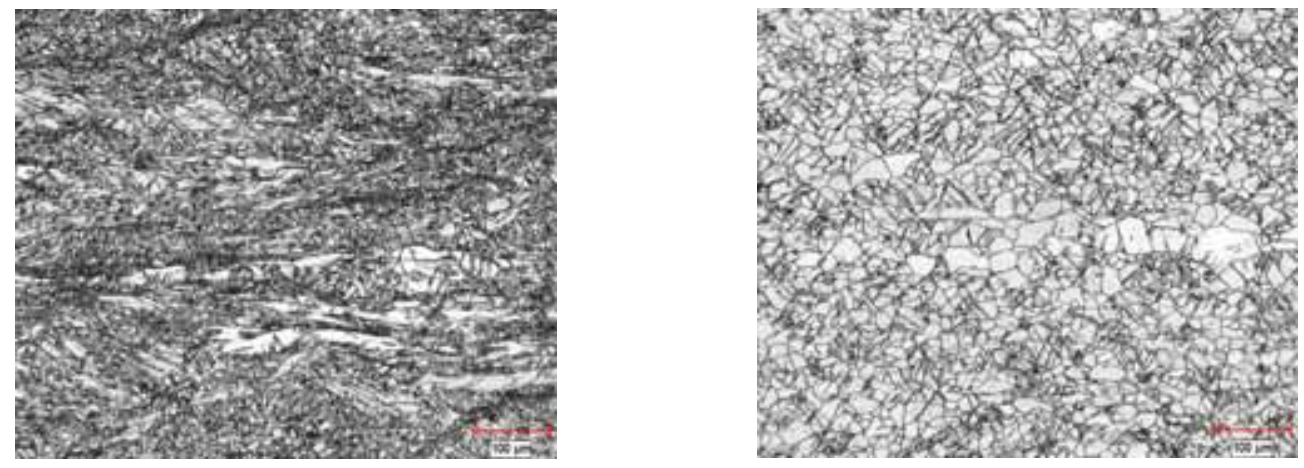

Fig. 16. As-rolled microstructures of an AZ31 sheet; rolling at $350^{\circ} \mathrm{C}$ (left) and $450^{\circ} \mathrm{C}$ (right) (Vespa et al., 2008). 


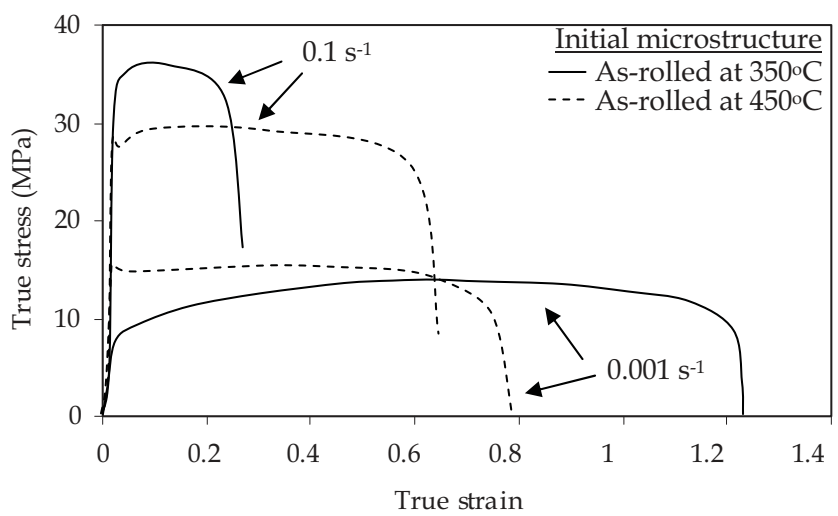

Fig. 17. Tensile deformation curves at $450^{\circ} \mathrm{C}$ corresponding with the microstructures in Fig. 16 (Vespa et al., 2008).

structure with an average grain size of $2.2 \mu \mathrm{m}$ (water-quenched microstructure) (Minamiguchi et al., 2006; Sakai et al., 2006 \& Utsunomiya, 2006). Such a high rolling speed also enhanced the rollability of AZ31 sheet in that $60 \%$ reduction in thickness was achieved in a single rolling pass. Since AZ31 alloy does not recrystallize at $200^{\circ} \mathrm{C}$ at conventional rolling speeds (Zarandi et al., 2007), the driving force and thermal energy required for recrystallization at $200^{\circ} \mathrm{C}$ are obviously provided by the amount of strain and very high strain rate, respectively. Although it seems difficult to implement such a high rolling speed in conventional sheet production, it introduces a new area of research to advance magnesium sheet properties. The outcome of such research would certainly help optimize rolling schedules to suit forming conditions.

\section{Summary and remarks}

Research into the production, deformation, and failure of magnesium alloys has provided a wealth of experimental information during the past decade. Such knowledge forms a critical basis for the development of magnesium sheet alloys. In considering the structure of magnesium and its impact on deformation and failure behavior, the grain size is more influential than it is in cubic metals, in that it also influences the relative contributions of different slip systems and deformation mechanisms to the overall flow. Strain hardening in magnesium alloys cannot be explained by the conventional models based on the Hall-Petch relationship. Solute elements and precipitates can generate anistropic characteristics by favoring one deformation mechanism or slip system over the other and affect both evolution of microstructure and mechanical properties. Moreover, orientations of basal planes have crucial impacts on the flow behavior and formability.

The absence of commercial magnesium sheet in automobile and other applications clearly indicates that more investigations and progress are still required. It is conceivable that magnesium sheets, capable of competing with commercial sheets of aluminum and steel, can be achieved through research and development in (i) sheet production technology and (ii) sheet characteristics and fabrication. In the former, the objective is to avoid intricate and multi-pass rolling schedules combined with intermediate annealing treatments. Twin-roll casting seems a promising approach toward this goal. The current research on magnesium 
twin-roll casting has concentrated on producing wider and longer sheets by improving the casting and coil rolling technologies. However, development of magnesium alloys which capitalize on the twin-roll cast microstructure, i.e. supersaturated matrix with dispersion of fine particles, is urgently required. AZ series alloys with $\mathrm{Al}$ content higher than $3 \mathrm{wt} \%$ as well as high Mn content alloys can be good candidates in this respect. Alloys with fine particles distributed throughout the microstructure and stable at elevated temperatures are especially important for randomizing the texture.

With regard to texture, sheet formability is the main issue, as this controls the successful fabrication of complex shapes in a timely manner. The evolution of microstructure and recrystallization are rather complicated processes in magnesium alloys. More systematic and detailed studies are required to understand underlying mechanisms. Topics such as twin-dislocation interactions, recrystallization kinetics, evolution of texture and slip systems during deformation, solute drag effect and superplasticity, superplasticity in coarse grain alloys, and effect of strain rate on formability at very fine grain sizes are among those which still need thorough investigation. Computational simulations and modeling, which have already aided progress in understanding the development of texture and slip mechanisms, should also be utilized to achieve the goal. Constitutive equations available for deformation of magnesium do not incorporate recrystallization during deformation. There is a requirement for comprehensive constitutive models that not only consider the evolution of microstructure during deformation, but also are based on multi-, rather than single, mechanism of deformation.

\section{References}

Alico, J. (1945). Forging, Rolling, Forming, and Extruding Magnesium Alloys, In: Introduction to Magnesium and its Alloys, Ziff-Davis Publication, New York.

Allen, R.V.; East, D.R.; Johnson, T.J.; Borbidge, W.E. \& Liang, D. (2001). Magnesium alloy sheet produced by twin roll casting, Proceedings of Magnesium Technology 2001, pp. 75-79, New Orleans, Louisiana, February 11-15, 2001, The Minerals, Metals, and Materials Society, USA.

Bach, Fr.-W; Rodman, M.; Rossberg, A. \& Hepke, M. (2006). Magnesium sheet production today and tomorrow, Proceedings of Magnesium Technology in the Global Age, pp. 255268, Montreal, Canada, 2006, Canadian Institute of Mining, Metallurgy and Petroleum, Montreal, Canada.

Barnett, M.R. (2003). A Taylor model based description of the proof stress of magnesium AZ31 during hot working. Metallurgical and Materials Transactions, 34A, 2003, 17991806.

Barnett, M.R.; Keshavarz, Z.; Beer, A.G. \& Atwell, D. (2004). Influence of grain size on the compressive deformation of wrought Mg-3Al-1Zn", Acta Materialia, 52, 2004, 50935103.

Cottam, R.; Robson, J. \& Lorimer, G. (2006). The deformation and recrystallization of commercially pure $\mathrm{Mg}$ and $\mathrm{Mg}-\mathrm{Y}$ alloys. Proceedings of Magnesium Technology in the Global Age, pp. 171-180, Montreal, Canada, October 2006, Canadian Institute of Mining, Metallurgy and Petroleum, Montreal, Canada.

CSIRO (2003). Thin magnesium sheet technology is ready to roll. www.manufacturingtalk.com, November 27, 2003. 
De La Torr, A.; Adeva, P. \& Aballe, M. (1991). Indentation creep of lead and lead-copper alloys. eburnal of Materials Science, 26, 16, 1991, 4351-4354.

Del Valle, J.A.; Pérez-Prado, M.T. \& Ruano, O.A. (2005). Deformation mechanisms responsible for the high ductility in a $\mathrm{Mg}$ AZ31 alloy analyzed by electron backscattered diffraction. Metallurgical and Materials Transactions A, 36, 6, 2005, 1427-1438.

Di, H.-S.; Li, Y.-L.; Ning, Z.-L.; Li, Z.; Liu, X. \& Wang, G.-D. (2005). New processing technology of twin roll strip casting of AZ31B magnesium strip", Materials Science Forum, Vols. 488-489, 2005, 615-618.

Dow Chemical Company (1943). Dowmetal Magnesium Alloys, Dow Chemical Company, Midland, Michigan, May, 1943.

Galiyev, A.; Kaibyshev, R. \& Gottstein, G. (2001). Correlation of plastic deformation and dynamic recrystallization in magnesium alloy AZ60. Acta Materialia, 49, 2001, 11991207.

Galiyev, A.; Kaibyshev, R. \& Sakai, T. (2003). Continuous dynamic recrystallization in magnesium alloy. Materials Science Forum, Vols. 419-422, 2003, 509-514.

Ion, S.E.; Humphreys, F.G. \& White, S.H. (1982). Dynamic recrystallization and the development of microstructure during the high temperature deformation of magnesium. Acta Metallurgica, 30, 1982, 1909-1982.

Jiang, L. (2008). Effect of twinning on texture and strain hardening in magnesium alloys subjected to different strain paths. PhD thesis, 2008, McGill University, Montreal, Canada.

Jung, I.-H.; Bang, W.; Kim, I.J.; Sung, H.-J.; Park, W.-J.; Choo, D. \& Ahn, S. (2007). Mg Coil Production via Strip Casting and Coil Rolling Technologies, Proceedings of Magnesium Technology 2007, pp. 85-88, Orlando, Florida, 2007, The Minerals, Metals, and Materials Society, USA.

Kaibyshev, R.O.; Galiev, A.M. \& Sokolov, B.K. (1994). Effect of grain size on the plastic deformation and dynamic recrystallization of a magnesium alloy. Physics of Metals and Metallogrophy, 78, 2, 1994, 209-217.

Kaibyshev, R. \& Sitdikov, O. (1994). Dynamic recrystallization of magnesium at ambient temperature. Z. Metallkd, 85, 10, 1994, 738-743.

Kaibyshev, R. \& Sitdikov, O. (1995a). Mechanisms of plastic deformation in magnesium: I. deformation behavior of coarse-grained magnesium. Physics of Metal and Metallography, 80, 1995, 354-360.

Kaibyshev, R. \& Sitdikov, O. (1995b). Mechanisms of plastic deformation in magnesium: II. analysis of activation processes. Physics of Metal and Metallography, 80, 1995, 470-475.

Kim, W.J.; Chung, S.W.; An, C.W. \& Higachi, K. (2001). Superplasticity in a relatively coarsegrained AZ61 magnesium alloy. eburnal of Materials Science Letters, 20, 2001, 16351637.

Kobayashi, T.; Koike, J.; Yoshida, Y.; Kamado, S.; Suzuki, M.; Maruyama, K. \& Kojima, Y. (2003). Grain size dependence of active slip systems in an AZ31 magnesium alloy. cburnal of the elopan Institute of Metals, 67, 4, 2003, 149-152. 
Koike, J.; Kobayashi, T.; Mukai, T.; Watanabe, H.; Suzuki, M.; Maruyama, K. \& Higachi, K. (2003). The activity of non-basal slip systems and dynamic recovery at room temperature in fine-grained AZ31B magnesium alloy. Acta Materialia, 51, 2003, 2055-2065.

Liang, D. \& Cowley, C.B. (2004). The Twin-Roll Casting of Magnesium. .DM, May 2004, 2628.

Masoumi, M.; Zarandi, F. \& Pekguleryuz, M. (2010a). Microstructure and Texture Studies on Twin-Roll Cast AZ31 (Mg-3wt\%Al-1wt\%Zn) Alloy and the Effect of Thermomechanical Processing, Materials Science and Engineering, in press, 2010.

Masoumi, M.; Zarandi, F. \& Pekguleryuz, M. (2010b). Alleviation of basal texture in twinroll cast Mg-3Al-1Zn alloy. Scripta Materialia, 62, 2010, 823-826.

Meyers, M.A.; Vohringer, O. \& Lubarda, V.A. (2001). The onset of twinning in metals: a constitutive description. Acta Materialia, 49, 2001, 4025-4039.

Minamiguchi, S.; Sakai, T.; Utsunomiya H. \& Koh, H. (2006). Improvement of mechanical properties of AZ31B sheets by high speed rolling, Proceedings of Magnesium Technology in the Global Age, pp. 217-227, Montreal, Canada, October 2006, Canadian Institute of Mining, Metallurgy and Petroleum, Montreal, Canada.

Miura, H.; Sakai, T.; Nogawa, H.; Yang, X.; Watanabe, Y. \& Miura S. (2005). Orientation dependence of ductility of $\mathrm{Mg}$ single crystals at elevated temperature. Materials Science Forum, Vols. 488-489, 2005, 193-196.

Mukai, T.; Mohri, T.; Mabuchi, M.; Nakamura, M; Ishikawa, K. \& Higashi, K. (1998). Experimental study of a structural magnesium alloy with high absorption energy under dynamic loading. Scripta Materialia, 39, 9, 1998, 1249-1253.

Mukai, T.; Watanabe, H.; Ishikawa, K. \& Higashi, K. (2003). Guide for enhancement of room temperature ductility in $\mathrm{Mg}$ alloys at high strain rates. Materials Science Forum, vols. 419-422, 2003, 171-176.

Nakaura, Y. \& Ohori, K. (2005). Properties of AZ31 magnesium alloy sheet produced by twin roll casting. Materials Science Forum, Vols. 488-489, 2005, 419-426.

Obara, T.; Yoshinaga, H. \& Morozumi, S. (1973). 11221123 slip system in Mg. Acta Metallurgica, 21, 7, 1973, 845-853.

Poss, R. (2003). Sheet metal production of magnesium. Materials Science Forum, Vols. 419-422, 2003, 327-336.

Roberts, C.S. (1964). The deformation of magnesium. Magnesium and Its Alloys, 81-107, John Wiley, New York.

Sakai, T. \& Jonas, J.J. (1984). Dynamic recrystallization: mechanical and microstructural considerations. Acta Metallurgica., 32, 1984, 189-209.

Sakai, T. (2000). Microstructural development under dynamic recrystallization of polycrystalline materials. Proceedings of Thermomechanical Processing of Steels (del Cbnas symposium), pp. 47-62, Ottawa, Canada, August 2000, Canadian Institute of Mining, Metallurgy and Petroleum, Montreal, Canada.

Sakai, T.; Utsunomiya, H.; Minamiguchi, S. \& Koh, H. (2006). Single pass large draught rolling of magnesium alloy sheets by high speed rolling, Proceedings of Magnesium Technology in the Global Age, pp. 205-215, Montreal, Canada, October 
2006, Canadian Institute of Mining, Metallurgy and Petroleum, Montreal, Canada.

Sastry, D.H.; Prasad, Y.V.R.K. \& Vasu, K.I. (1969). On the stacking fault energies of some closed-packed hexagonal metals. Scripta Metallurgica, 3, 1969, 927-930.

Senn, J.W. \& Agnew, S.R. (2008). Texture randomization of magnesium alloys containing rare earth elements. Proceedings of Magnesium Technology 2008, pp. 153-158, New Orleans, Louisiana, 2008, The Minerals, Metals, and Materials Society, USA.

Sitdikov, O. \& Kaibyshev, R. (2001). Dynamic recrystallization in pure magnesium. Materials Transactions, 142, 9, 2001, 1928-1937.

Sitdikov, O.; Kaibyshev, R. \& Sakai, T. (2003). Dynamic recrystallization based on twinning in coarse-grained Mg. Materials Science Forum, Vols. 419-422, 2003, 521-426.

Stohr, J.F. \& Poirier, J.P. (1972). Electron-microscope study of pyramidal slip 11221123 in Mg. Philosophical Magazine, 25, 6, 1972, 1313-1329.

Taylor, G.I. (1938). Plastic strain in metals. eburnal of Institute of Metals, 62, 1938, 307-324.

Uesugi, T.; Kohyama, M.; Kohzu, M. \& Higashi, M. (2003). Generalized stacking fault energy and dislocation properties for various slip systems in magnesium: a first-principles study. Materials Science Forum, Vols. 419-422, 2003, 225-230.

Utsunomiya, H.; Sakai, T.; Minamiguchi, S. \& Koh, H. (2006). High speed heavy rolling of magnesium alloy sheets, Proceedings of Magnesium Technology 2006, pp. 201-204, San Antonio, Texas, March 2006, The Minerals, Metals, and Materials Society, USA.

Valle, J.A. del; Carreno, F. \& Ruano, O.A. (2006). Influence of texture and grain size on work hardening and ductility in magnesium-based alloys processed by ECAP and rolling. Acta Materialia, 54, 2006, 4247-4259.

Vespa, G.; Mackenzie, L.W.F.; Verma, R.; Zarandi, F.; Elhachmi, E. \& Yue, S. (2008). The influence of the as-hot rolled microstructure on the elevated temperature mechanical properties of magnesium AZ31 sheet. Materials Science and Engineering A, 487, 2008, 243-250.

Watanabe, H. \& Mukai, T. (1999). Superplasticity in a ZK60 magnesium alloy at low temperatures. Scripta Materialia, 40, 4, 1999, 477-484.

Watanabe, H.; Tsutsui, H.; Mukai, T.; Ishikawa, K.; Okanda, Y.; Kohzu, M. \& Higashi, K. (2001). Grain size control of commercial wrought Mg-Al-Zn alloys utilizing dynamic recrystallization. Materials Transactions, 42, 2001, 1200-1205.

Wonsiewiczs, B.C. \& Backofen, W.A. (1967). Plasticity of magnesium crystals. Transactions of TMS-AIME, 239, 1967, 1422-1431.

Yang, C.; Ding, P.; Zhang, D. \& Pan, F. (2005). The Microstructure and processing in twin roll casting of magnesium alloy strip. Materials Science Forum, Vols. 488-489, 2005, 427-430.

Zarandi, F.; Verma, R.; Yue, S. \& Essadiqi, E. (2007). Microstructure evolution during rolling of AZ31 magnesium alloy under decreasing temperature, Proceedings of Magnesium Technology 2007, pp. 75-80, Orlando, Florida, 2007, The Minerals, Metals, and Materials Society, USA. 
Zarandi, F.; Seale, G.; Verma, R.; Essadiqi, E. \& Yue, S. (2008). Effect of Al and Mn additions on rolling and deformation behavior of AZ series magnesium alloys. Materials Science and Engineering A, 496, 2008, 159-168. 


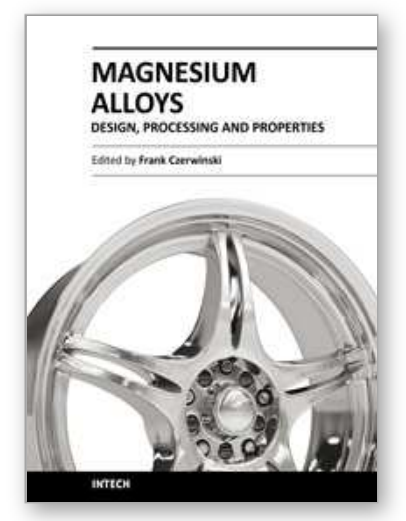

\author{
Magnesium Alloys - Design, Processing and Properties \\ Edited by Frank Czerwinski
}

ISBN 978-953-307-520-4

Hard cover, 526 pages

Publisher InTech

Published online 14, January, 2011

Published in print edition January, 2011

Scientists and engineers for decades searched to utilize magnesium, known of its low density, for lightweighting in many industrial sectors. This book provides a broad review of recent global developments in theory and practice of modern magnesium alloys. It covers fundamental aspects of alloy strengthening, recrystallization, details of microstructure and a unique role of grain refinement. The theory is linked with elements of alloy design and specific properties, including fatigue and creep resistance. Also technologies of alloy formation and processing, such as sheet rolling, semi-solid forming, welding and joining are considered. An opportunity of creation the metal matrix composite based on magnesium matrix is described along with carbon nanotubes as an effective reinforcement. A mixture of science and technology makes this book very useful for professionals from academia and industry.

\title{
How to reference
}

In order to correctly reference this scholarly work, feel free to copy and paste the following:

Faramarz Zarandi and Stephen Yue (2011). Magnesium Sheet; Challenges and Opportunities, Magnesium Alloys - Design, Processing and Properties, Frank Czerwinski (Ed.), ISBN: 978-953-307-520-4, InTech, Available from: http://www.intechopen.com/books/magnesium-alloys-design-processing-andproperties/magnesium-sheet-challenges-and-opportunities

\section{INTECH}

open science | open minds

\author{
InTech Europe \\ University Campus STeP Ri \\ Slavka Krautzeka 83/A \\ 51000 Rijeka, Croatia \\ Phone: +385 (51) 770447 \\ Fax: +385 (51) 686166 \\ www.intechopen.com
}

\author{
InTech China \\ Unit 405, Office Block, Hotel Equatorial Shanghai \\ No.65, Yan An Road (West), Shanghai, 200040, China \\ 中国上海市延安西路65号上海国际贵都大饭店办公楼405单元 \\ Phone: +86-21-62489820 \\ Fax: +86-21-62489821
}


(C) 2011 The Author(s). Licensee IntechOpen. This chapter is distributed under the terms of the Creative Commons Attribution-NonCommercialShareAlike-3.0 License, which permits use, distribution and reproduction for non-commercial purposes, provided the original is properly cited and derivative works building on this content are distributed under the same license. 